\title{
Improvement Mode of Informatization Teaching Ability under Double Blended Learning-Driven
}

Tian-Tian Feng ${ }^{1 *}$, Ming-Li Cui ${ }^{2}$

${ }^{1}$ School of Economics and Management, China University of Geosciences, Beijing, China, 100083

${ }^{2}$ School of Economics and Business Administration, Heilongjiang University, Harbin, China, 150080

DOI: $10.36348 /$ jaep.2020.v04i12.002

| Received: 26.11.2020 | Accepted: 05.12.2020 | Published: 16.12.2020

*Corresponding author: Tian-Tian Feng

\section{Abstract}

Teachers' blended teaching ability refers to the ability of teachers to use both online and offline occasions and scenes for blended teaching. At present, the blended teaching ability of teachers in China University of Geosciences (Beijing) is still insufficient, which affects the effectiveness and quality of blended teaching. This paper puts forward the improvement mode of informatization teaching ability under "double blended learning-driven", that is, to transfer to the "blended" teacher teaching through the "blended" teacher training. Starting from the inscapes and existing problems of teachers' blended teaching ability in universities and colleges, this paper creates a flexible training mode of teachers' blended teaching ability in universities and colleges, taking the major of Business Administration as an example, giving an effective way to improve teachers' informatization teaching ability, so as to provide reference for the university to design and optimize the mode of teacher training.

Keywords: Informatization, Blended Teaching, Teaching Ability, Flexible Training.

Copyright (9) 2020 The Author(s): This is an open-access article distributed under the terms of the Creative Commons Attribution 4.0 International License (CC BY-NC 4.0) which permits unrestricted use, distribution, and reproduction in any medium for non-commercial use provided the original author and source are credited.

\section{INTRODUCTION}

Teachers are the decisive and key factors in teaching activities. Teachers' teaching ability directly affects or even determines the level of teaching quality. Teachers' blended teaching ability refers to the ability of teachers to use both online and offline occasions and scenes for blended teaching. At present, blended teaching combines the advantages of traditional teaching, modern information technology and network technology education, featuring combination of online learning and offline teaching as well as of students' autonomous learning and teachers' monitoring and guidance, theoretical learning and practical operation, integration of doing and learning and other characteristics. Therefore, it has been highly promoted by colleges and universities in recent years. But at present, teachers in our university are generally in lack of blended teaching ability, which affects the effectiveness and quality of blended teaching, and has become a bottleneck problem restricting the implementation of blended teaching as well as an urgent issue to be studied and solved $[1,2]$.

Putting forward the improvement mode of informatization teaching ability under "double blended learning-driven", this paper means to transfer to "blended" teacher teaching through "blended" teacher training. That is, to quickly switch the "blended learning" that teachers have experienced in the training to their own "blended teaching". In the past, the "blended" teacher training was only to teach teachers how to use different online and offline platforms in their teaching, but how to well integrate the two, and the operability and practicality are still unsatisfactory. As young teachers in universities, we are eager to apply the teaching mode and skills learned in the training to our own teaching activities. However, at present, although our university has implemented some training, the content is complex and repetitive, lacking systematicness and pertinence; especially for teachers who are not familiar with the online operation, various situations may arise in the teaching process; and the input of training resources is chaotic due to poor understanding of the ability of teachers of different types and different operational levels; meanwhile, compare with undergraduate teaching, some graduate teaching need not only the teaching of professional knowledge, but also the guidance of social practice (such as the major of business administration) and research-oriented content, however, at present, only offline guidance can be used for these two aspects, and no suitable blended teaching mode has been found. From this point of view, at present, our understanding 
and exploration of informatization teaching is far from enough. Starting from the inscapes and existing problems of teachers' blended teaching ability in universities and colleges, this paper creates a flexible training mode of teachers' blended teaching ability in universities and colleges, taking the major of Business Administration as an example, giving an effective way to improve teachers' informatization teaching ability, so as to provide reference for the university to design and optimize the mode of teacher training $[3,4]$.

\section{Analysis on the inscapes of teachers' informatization teaching ability in colleges and universities \\ Characteristics of the major of Business Administration \\ The major of Business Administration of} School of Economics and Management of China University of Geosciences (Beijing) was first established in 1986, and has continuously carried out the reform of teaching and research, so that the characteristics in respect of compound talents have been strengthened and highlighted. Its major orientation is: guided by the demand of resource-based enterprises and talents in jewelry business, relying on the characteristics of the university's resources and environment, and adhering to the university's management concept of "entering the mainstream with characteristics", to train compound talents for resourcebased enterprise management and jewelry business application who carry with humanistic spirit, scientific literacy, international vision, local feelings, innovative consciousness and team spirit, and can exert influence in China, so as to build a nation-wide first-class major with distinctive industrial characteristics.

The characteristics and advantages of the major of Business Administration are: 1) It intensifies the cross integration with resource science and gemology. Relying on the resources, environment and geological advantages of the University, as well as the basic theory of this discipline, it has established the major of Business Administration (Earth Science and business), setting up a series of characteristic professional courses such as resource-based enterprise management and jewelry business affairs, and building up a characteristic talent training system with the combination of resources, environment, jewelry and the major itself. 2) It builds up a practical teaching system with the characteristics of resource-based enterprise management and jewelry business affairs. By promoting the cooperation between university and enterprise, it has joint hands with 22 enterprises of various types to build internship bases and has employed managers from mining companies and jewelry companies to guide practical teaching, and has developed the characteristic internship software with independent intellectual property rights for professional courses. 3) It deepens the reform of talent training mode. It has first promoted the undergraduate tutorial system in the university, established the "double tutor" training mode by virtue of enterprises and excellent teaching staff, building a talent training mechanism of "Undergraduate-Master-Doctor", setting up "Sino-US International Economic Management Classroom" to explore a new way to develop international compound talents [5].

It can be seen that the major of Business Administration is actually a major closely combined with the needs of social economy, industrial characteristics and enterprise practices. In recent years, we are also committed to creating a "Trinity" talent training mode to achieve classified training, including: 1) training professional knowledge through classroom learning; 2) developing scientific literacy through academic research training; 3) cultivating practical ability through social practice. These models are more and more inseparable from the informatization teaching ability of teachers in colleges and universities. We need to make use of the advantages of modern information technology and network technology education, give full play to students' autonomous learning ability and practical ability, and develop teachers' ability to expand teaching content and enrich teaching methods. However, there are still some problems, such as the teaching concept is not advanced enough, the development and construction of professional courses are not enough, the ability of blended teaching design is insufficient, and the construction of teaching resources is not complete.

\section{Construction of four modules of informatization teaching ability}

Based on literature research and investigation, this paper divides the informatization teaching ability into four modules, including: < $1>$ the ability in the development of practice course of the major of Business Administration (professional level), <2 > the blended teaching design for courses and online-offline organizing ability of teaching (professional + technical level), < (3) > construction ability for informatization course resources (professional + technical level), and < (4) > the ability to use the blended course platform (technical level) and so on. Hereby it is called the four abilities (4A) module, as shown in Fig-1. 


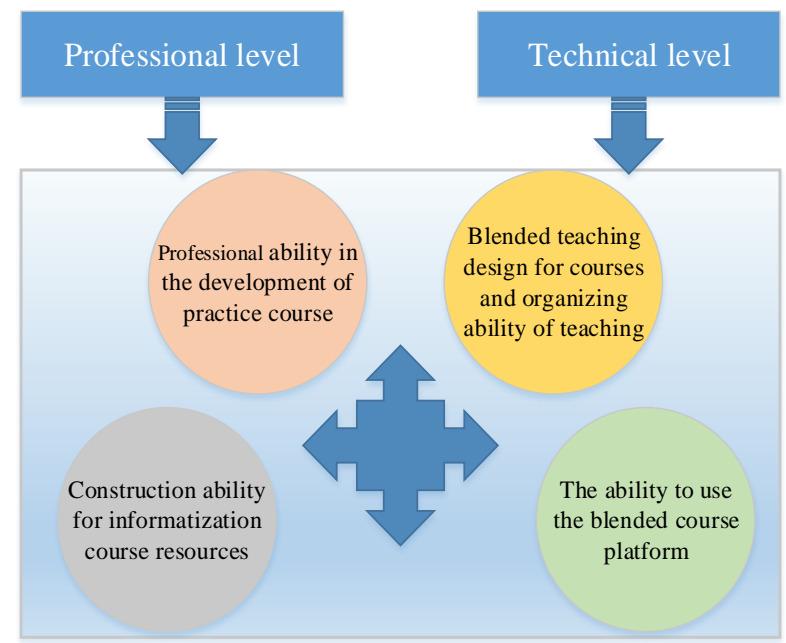

Fig-1: Composition of four abilities of informatization teaching of teachers in universities

Survey on innovative training mode of blended teaching ability of teachers in colleges and universities

There are many training modes for teachers' teaching ability in colleges and universities (including blended teaching ability), and the training of teachers of colleges and universities through blended mode has become a new way of teacher training supported by Internet technology. We have studied some typical innovation modes for blended training that have been implemented in China, including: the whole-process blended training mode supported by information technology, the task-driven flipped blended training mode, the regional NAEA blended training mode based on problem solving, and the blended training mode of "online training and teaching" based on interactive live broadcast technology, etc (as shown in Fig-2). These are modes that all aim to enhance the blended teaching ability of teachers in colleges and universities through blended training, so as to achieve the enhancement of the "Double Blended Learning-driven" teachers' informatization teaching ability. This is conducive to the learning and application transfer of blended teaching methods for the major of Business Administration, and lays a practical foundation for the differentiated customization and precise selection of subsequent training modes.

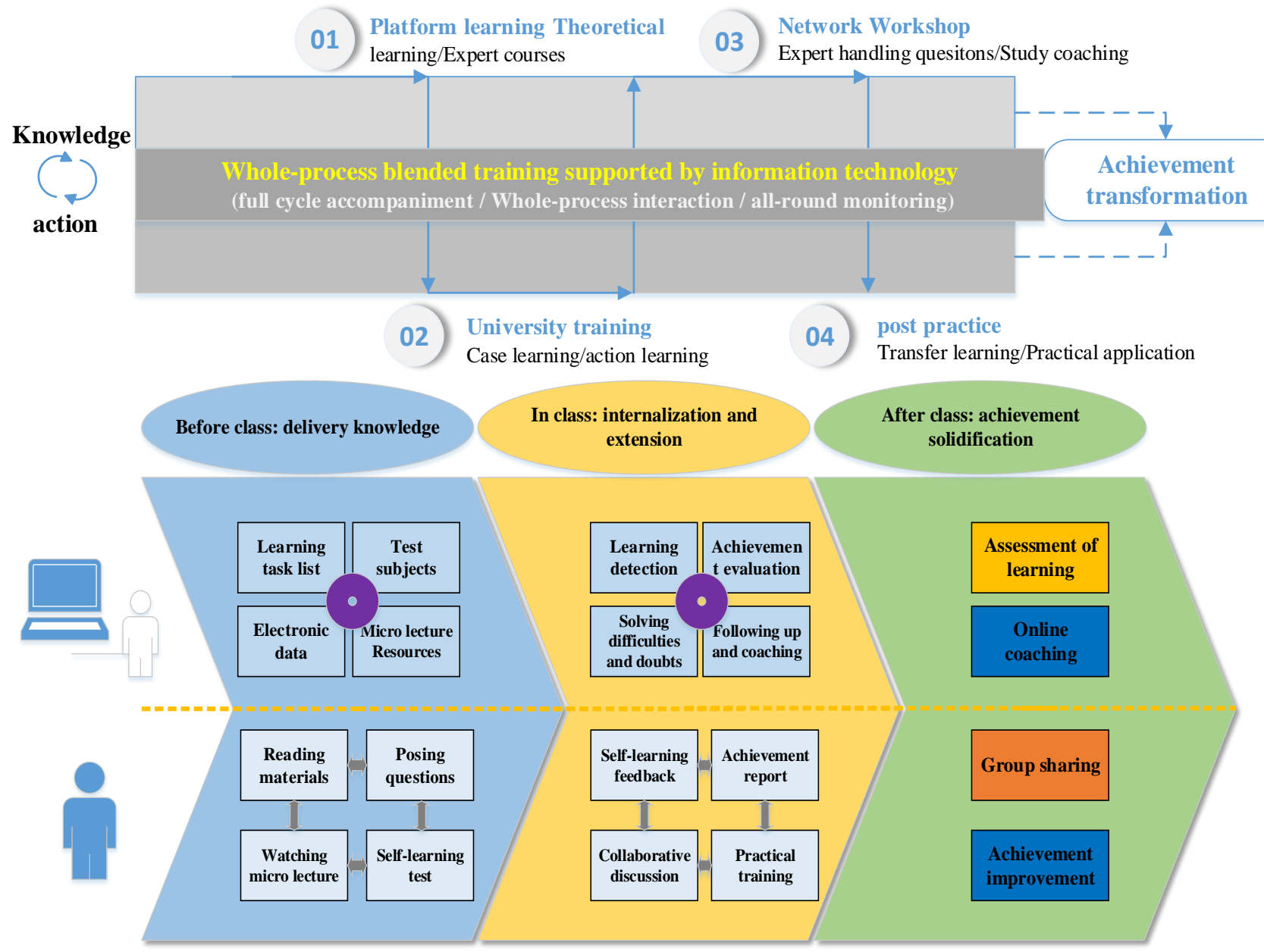

Whole-process blended training mode Task-driven flipped blended training mode 


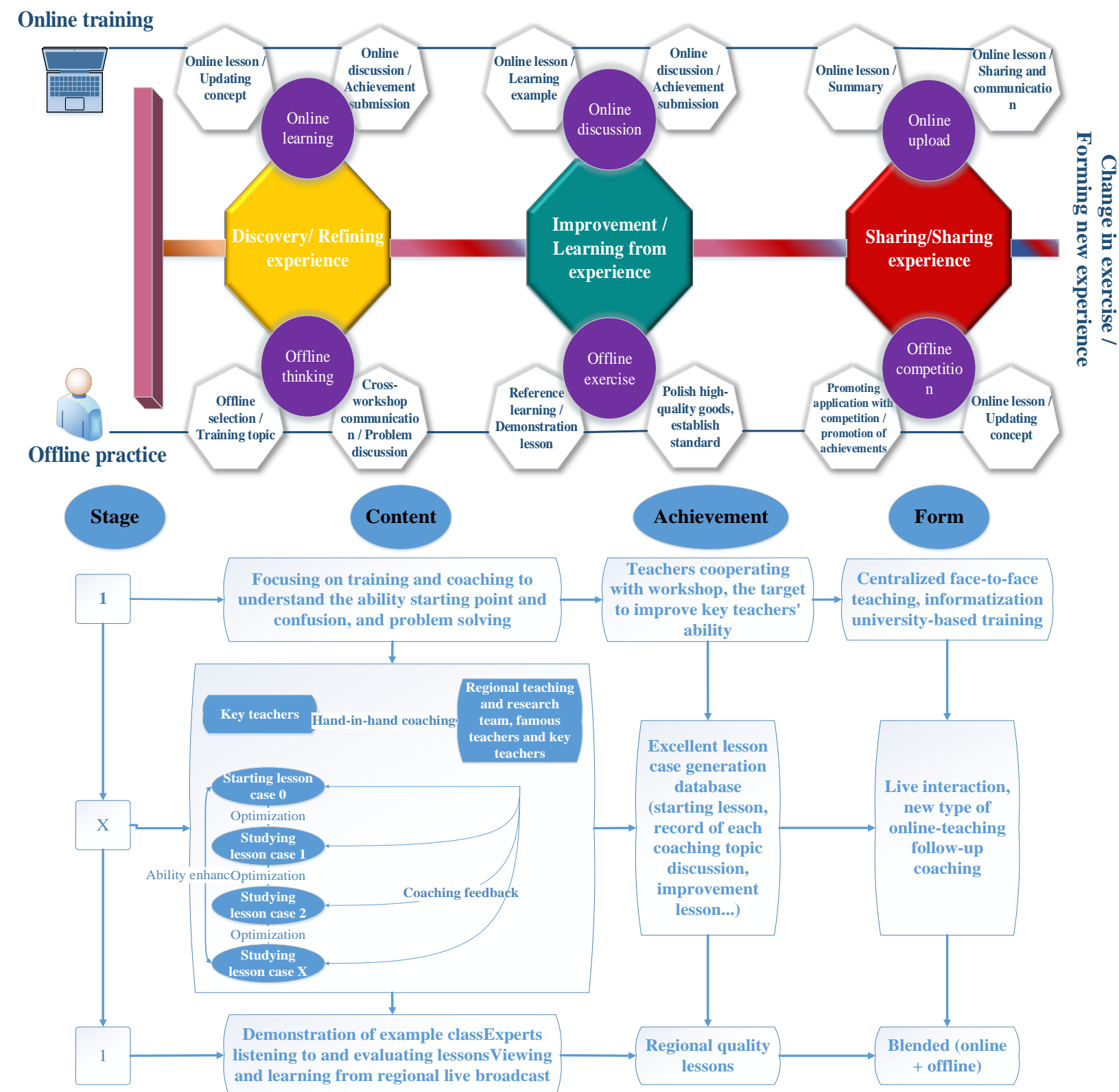

Regional NAEA blended training mode based on problem solving Blended training mode of "online training and teaching" based on interactive live broadcast technology

Fig-2: Typical innovation modes for blended training

\section{Design of flexible training mode for blended teaching ability of teachers in colleges and universities}

In view of the four abilities (4A) in teachers' informatization teaching in colleges and universities proposed in 2.2, combined with the innovation modes for blended training in the third part, and based on the five inscapes theory (Platform、Course、Activity 、 Evaluation 、 Management, PCAEM), a flexible training mode of University Teachers' blended teaching ability is constructed, which is also called "4APCAEM" O2O (online to offline) research and training mode, that is, PCAEM training is carried out for each ability module, so as to improve its informatization teaching ability step by step. The "flexibility" hereby means that the $\mathrm{O} 2 \mathrm{O}$ mode can select or customize different blended innovation modes according to different situations, so as to achieve selective, iterative, renewable and replaceable effects.

The $\mathrm{O} 2 \mathrm{O}$ blended training mode of teachers from the perspective of "4A-PCAEM" includes: 1) platform, which is used to provide high-quality learning resources and expert-level consulting services for trained teachers, and realize information sharing, participants' interaction, and monitor their learning process, learning effect and information feedback. 2) Course system, which will design special courses according to different ability modules to be improved, and then refines the knowledge points of each subject, and further establishes the association between subjects, and forms the advanced system of course network. 3) Activity, which is designed to have two parts--online 
and offline. Online learning activities are mainly conducted by trainees (trained university/college teachers), and supplemented by the supervision and management activities of trainers. Offline activities are mainly based on communication and supplemented by on-site evaluation. This also lays the foundation for the trained teachers to transfer this mode to their own teaching activities. 4) Evaluation, which builds an evaluation system for training effect of $\mathrm{O} 2 \mathrm{O}$ training model to provide comprehensive evaluation on online learning activities, offline training and practice activities. 5) Management, which divides the whole management process of research and training into four stages according to PDCA cycle theory: Plan、Do、

Check 、 Act. The corresponding performance measurement indicators and process control methods are formulated to ensure the effective implementation of the overall model.

Case scenario on the improvement of blended teaching ability of teachers in colleges and universities -- taking the major of Business Administration as an example

According to the construction process of "4APCAEM" O2O training mode proposed in the fourth part, based on the learning transfer theory, and by virtue of the teaching and relevant experience of the teaching staff of the major of Business Administration of the School of Economics and Management, the blended teaching ability of teachers of the major of Business Administration will be further improved.

First of all, identify the training requirements of the trainees in respect of the four ability modules ( 4 Abilities, 4A: the ability in the development of practice course of the major of Business Administration, the blended teaching design for courses and online-offline organizing ability of teaching, construction ability for informatization course resources, and the ability to use the blended course platform) through ways such as preliminary research and communication with them so as to improve their blended teaching ability with targeted selection of $\mathrm{O} 2 \mathrm{O}$ blended training mode and platform (in accordance with the skills available to trained teachers) to train the teachers.

Set up special training for 4 Abilities, integrate teaching and research office and resources of the university, further develop training tasks, refine course content, including training modules, knowledge points, practice design, inspection methods, etc., so as to realize the refined delivery of knowledge points and thematic interconnection for trained teachers, and improve efficiency and effect. For example, in order to improve the development ability of practice courses for the major of Business Administration, the training content requires customized design, continuous research and update, including online and offline training of industry and industry development, course and enterprise, how to establish cooperation mechanism with enterprises, and build practice base. In order to improve the ability of online and offline guidance of research-oriented content that postgraduate teaching may concern about, we should design the training content according to the characteristics of graduate students.

Evaluation of the effect of improvement of blended teaching ability. After the $\mathrm{O} 2 \mathrm{O}$ on-line and offline blended training activities, it is necessary to evaluate the scheme for improving the blended teaching ability of the major of Business Administration, and construct a three-dimensional evaluation index system, which includes not only the performance evaluation of teachers' participation in training activities, but also the evaluation of teachers' practice results (that is, the teaching effect achieved by the trained teachers through using the blended teaching mode learned in the training to carry out their own classroom teaching). Finally, it needs to carry out satisfaction survey of the trained teachers, and propose the improvement mechanism and strategy of the above scheme to realize PDCA cycle.

\section{SUMMARY AND PROSPECT}

Based on the academic background of the major of Business Administration, and the teaching methods and experience of myself in universities, this paper proposes a flexible training mode of blended teaching ability, and develops the "4A-PCAEM" O2O training program to counter the current training problems on blended teaching ability in the university, that is, for each ability module (development of practice course, blended teaching design for courses, construction of informatization course resources and usage of the blended course platform) PCAEM training

( Platform 、 Course 、 Activity 、 Evaluation 、

Management) is carried out so as to improve their informatization teaching ability step by step. Finally, taking the teaching of the major of Business Administration as an example, this paper proposes a case scenario on the improvement of teachers' blended teaching ability in colleges and universities, selects innovative $\mathrm{O} 2 \mathrm{O}$ training mode, and sets special training for four ability modules. In the future, through further research and effect evaluation, it can realize the refined investment and interconnection of training resources, so as to spirally improve the blended teaching ability of teachers in this major.

\section{ACKNOWLEDGMENTS}

This paper is supported by the Postgraduate Education Reform Project of China University of Geosciences (Beijing) in 2020 (Improvement Mode of Informatization Teaching Ability under Double Blended Learning-driven, Grant No. YJG202002), and the Undergraduate Education Quality Improvement Project of China University of Geosciences (Beijing) in 2020 (Online and Offline Hybrid Course Construction of Management Principles, Grant No. HHSKE202011). 


\section{REFERENCES}

1. Yong-ping, T. (2019). Elements of Blended Teaching Ability of Higher Vocational Teachers and the Training Strategies. Higher Education Forum, 1:43-45.

2. Cheng-Ling, Z., Zhi-Hui, J., \& Hong-Xia, L. (2017). Research on the Construction of Teachers' Blended Training Mode from the Perspective of Five Elements. E-education Research, (3):110115.

3. Li, W., \& Xia-Chun, H. (2018). Practice and Reflection on the Blended University-based
Training of Higher Vocational Teachers' Informatization Teaching Ability in Network Learning Space. China Modern Educational Equipment, 281(1):63-64.

4. Xiao-Jin, W., \& Hai-Yin, S. (2016). Research on Blended Learning Mode of Pre-post Training for University Teachers Based on MOOC. China Modern Educational Equipment, 23:58-61.

5. Jiang, Y. (2019). Research on Blended Teacher Training under the Background of Mobile Internet. Journal of Fujian Institute of Education, 21(2):118-120. 